
T.

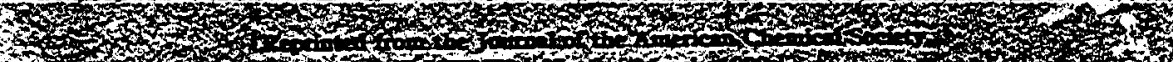

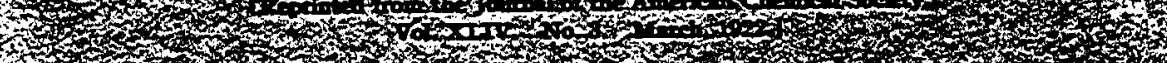

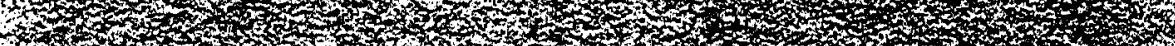

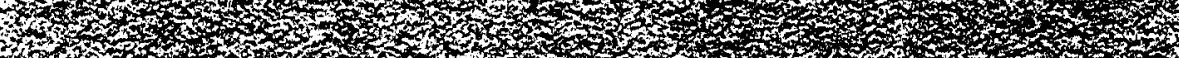

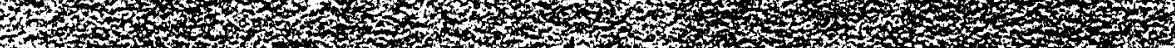

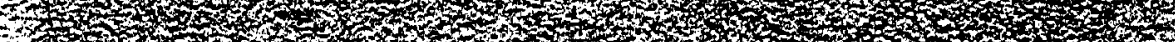

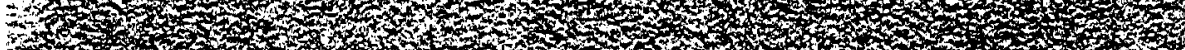

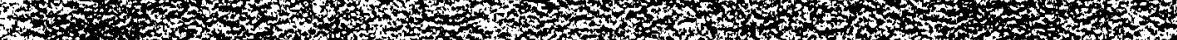

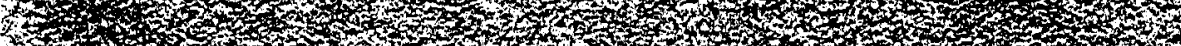

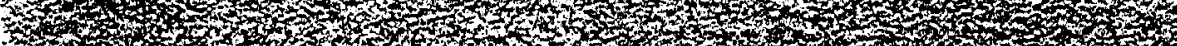

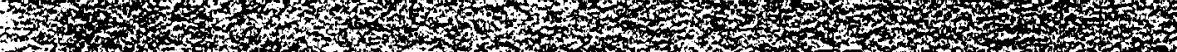

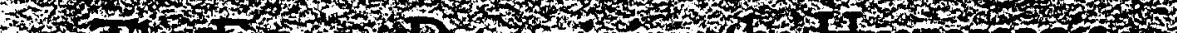

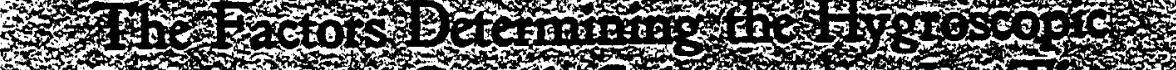

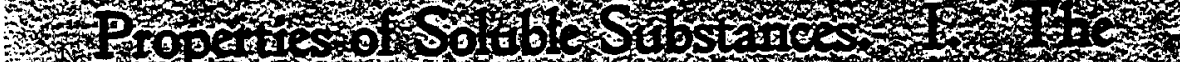

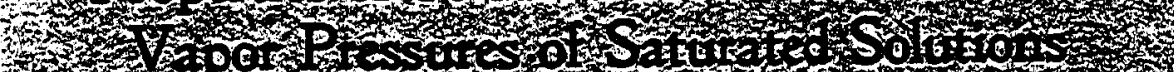

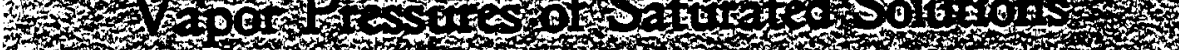

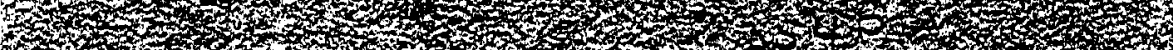

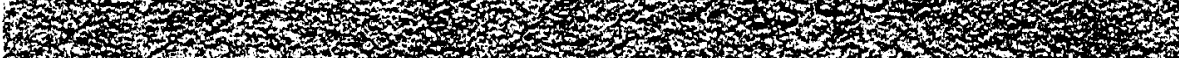
T,

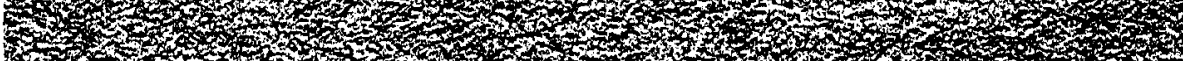

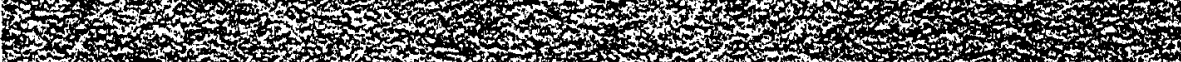

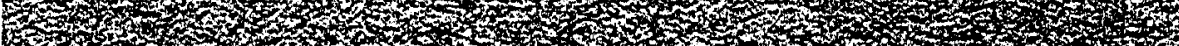

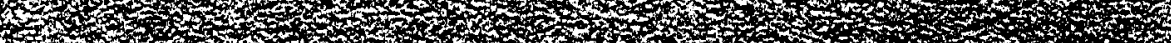

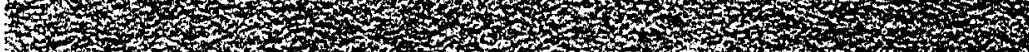

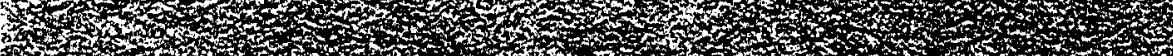

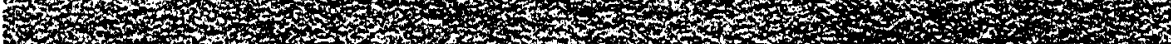

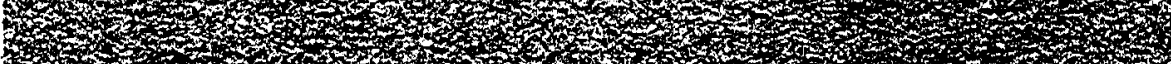
7. V.

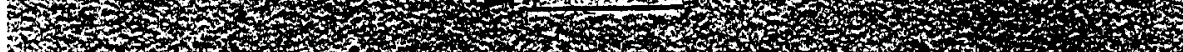
J

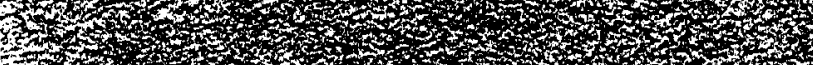

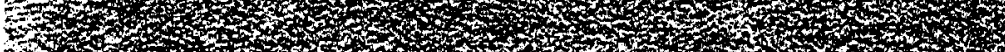

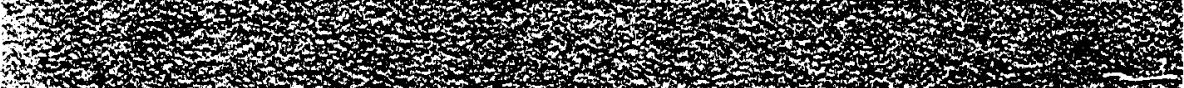
13

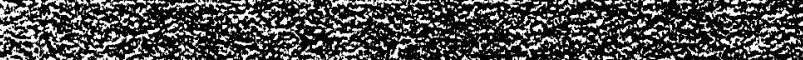

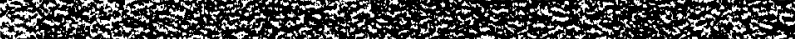

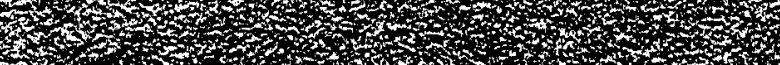

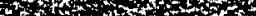


[Reprinted from the Journal of the American Chemical Society,

Vol. XLIV. No. 3. March, 1922.]

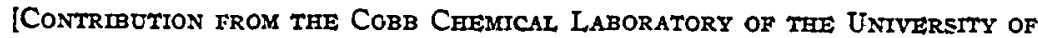
VIRGINIA] \pm 3

\title{
THE FACTORS DETERMINING THE HYGROSCOPIC PROPER- TIES OF SOLUBLE SUBSTANCES. I. THE VAPOR PRESSURES OF SATURATED SOLUTIONS
}

\author{
By Gramam Edgar and W. O. Swan'
}

Received December 26. 1921

\section{Introduction}

A dry, crystalline, water-soluble solid, not forming a crystalline hydrate, will, when exposed to air containing water vapor, tend to absorb moisture, with the formation of a saturated solution. If we neglect for the moment pure surface adsorption, such absorption can occur only when the vapor pressure of the saturated solution is lower than the partial pressure of water vapor in the atmosphere to which the solid is exposed. Since the vapor pressure of any aqueous solution is lower than that of pure water, any solid. will absorb moisture when exposed to saturated aqueous vapor, and is therefore to some extent "hygroscopic." This term, however, is commonly applied only to such substances as absorb moisture readily from air under normal atmospheric conditions.

Although the hygroscopic properties of commercial solids which are to be sold in other than sealed containers (for example, fertilizer salts) play an important part in limiting the commercial applications of such solids, no careful scientific study seems to have been made of the factors involved in determining the extent or rate of their absorption of moisture.

As indicated above, the vapor pressure of the saturated aqueous solution determines the partial pressure of water vapor with which the solid (and its saturated solution) may be in equilibrium; a solid may be expected to absorb moisture when exposed to an atmosphere containing more water vapor than this, and conversely the moist solid will lose water when exposed to an atmosphere containing a lower partial pressure of water vapor. The rate at which the moisture will be absorbed will depend upon a number of factors. We can predict from a priori considerations that the rate of moisture absorption will be affected by (1) the difference between the partial pressure of water vapor in the atmosphere and the

${ }^{2}$ Certain preliminary measurements were made by N. E. Ogiesby. 
vapor pressure of the saturated aqueous solution $\left(P_{\mathrm{H}: \mathrm{O}}-P_{\text {sat. sol. }}\right)$, (2) the temperature, (3) the surface of solid exposed, (4) the velocity of movement of the moist air, and (5) a specific "reaction constant," characteristic of the solid itself.

The present research represents an attempt to analyze as completely as may be possible the influence of the separate factors in determining the hygroscopic properties of typical water-soluble solids not forming crystalline hydrates. The substances selected for investigation were potassium, sodium and ammonium nitrates, potassium and ammonium chlorides, ammonium sulfate and dihydrogen orthophosphate, and urea. A mixture of potassium nitrate and ammonium chloride has also been studied. The selection was made to include substances of various degrees of solubility and of different chemical types. All of the substances studied have also a certain commercial interest.

Part 1 deals entirely with the measurement of the vapor pressures of the saturated aqueous solutions.

\section{Previous Data}

While large numbers of vapor-pressure measurements are recorded in the literature, very few data at all reliable are available upon the saturated aqueous solutions of the substances in question at low temperatures $\left(20-30^{\circ}\right)$.

Speranski2 measured the vapor pressures of saturated aqueous solutions of potassium and sodium nitrates and potassium chloride, using the Bremer-Frowein tensimeter. His results will be discussed below.

Hartung ${ }^{3}$ measured the vapor pressure of a saturated solution of potassium chloride, obtaining results not in good agreement with those of Speranski.

Lovelace, Frazer and Sease' made very careful measurements of the vapor pressure of potassium chloride solutions of different concentrations at $20^{\circ}$. By a very short extrapolation of their data the value for the saturated solution may be calculated.

Lincoln and Klein ${ }^{5}$ measured the vapor pressures at $25^{\circ}$ of sodium nitrate solutions sufficiently concentrated to permit extrapolation to the saturation value with reasonable confidence.

Measurements upon less concentrated solutions of a few of the substances in question ${ }^{6}$ may be extrapolated to the saturation point, but in most cases this extrapoLation must be carried too far to be reliable.

Lescoeuri measured the vapor pressures of the saturated solutions of a number of salts, but his values are in marked disagreement with those of all other investigators and are frequently in obvious error.

In view of the paucity of data and the lack of concordance in such data as exist, it was determined to measure the vapor pressures of satu-

2 Speranski, Z. physik. Chem., 70, 519 (1910) and 78, 86 (1912).

${ }^{3}$ Hartung, Trans. Faraday Soc., 15, [III] 150 (1920).

4 Lovelace, Frazer and Sease, ThIs JourNar, 43, 102 (1921).

s Lincoln and Klein, J. Phys. Chem., 11, 318 (1907).

- Landolt-Börnstein "Tabellen."

"Lescoeur, Ann: chim., [VII] 7, 416 (1896). 
rated aqueous solutions of the substances listed above at temperatures representing normal atmospheric conditions, namely $20-30^{\circ}$.

\section{Experimental Methods}

After consideration of several possible methods, that proposed by Smith and Menzies ${ }^{8}$ employing the isoteniscope, was selected. The apparatus and experimental technique were essentially those of Smith and Menzies, except for minor modifications.

The bulb of the isoteniscope was enlarged to contain about $15 \mathrm{cc}$., and a small trap was sealed in above it to guard against loss from the "bumping" which sometimes occurred. A heavy mineral oil, possessing no appreciable vapor pressure, was used as confining liquid, following the procedure of Derby and Yngve." The isoteniscope was connected to a 10-liter bottle as balancing reservoir, which in turn was connected to a 3-stage Cenco-Nelson pump, a manometer, and a side tube through which air could be admitted. The isoteniscope was maintained at constant temperature by immersion in an air-jacketed glass vessel of water, heated by a coil of glass tubing through which warm water could be circulated, and vigorously stirred by a turbine stirrer.

The thermometer used could be read to $0.01^{\circ}$, and had been compared with one calibrated by the Bureau of Standards. The manometer was of the closed type, constructed from 16-mm. Pyrex tubing (to minimize meniscus errors), and filled with carefully purified mercury. It was repeatedly boiled out to remove air. A glass scale, which had been compared with a standard meter, was placed directly behind the mercury column. Readings were made by means of a cathetometer, placed about a meter away, the millimeters being read directly from the glass scale, and the fractions estimated by means of the micrometer screw of the cathetometer, which permitted estimation to $0.01 \mathrm{~mm}$. The manometer was tapped continuously to avoid "sticking" of the mercury. All readings were reduced to millimeters of mercury, at $0^{\circ}$.

In carrying out a determination the procedure was as follows.

The bulb of the isoteniscope was filled about $2 / 3$ full of a mixture of the solid and water, a sufficient excess of solid being added to occupy about half of this volume. The bulb was then sealed to the rest of the apparatus, the pump started, and the apparatus evacuated until the contents of the buib boiled vigorously. After the boiling had continued for some time the pump was shut off, and air was admitted into the large bottle until the oil in the leveling tube showed no pressure difference between the bulb and the air reservoir. The manometer was then read and the process of boiling out repeated until 3 to 10 concordant readings had been obtained. Throughout the entire procedure the bulb was vigorously agitated. The temperature was then changed and the process repeated. Usually in making a series of determinations at different temperatures, measurements obtained at rising temperatures were repeated at falling temperatures to make sure that errors due to failure to achieve saturation of the solution might be detected.

8 Smith and Menzies, Thus Jourara, 32, 1921 (1910).

9 Derby and Yngve, ibid., 38, 1439 (1916). 
In order to check the correctness of the method measurements were made of the vapor pressure of pure water, first with water and then with oil as confining liquid. Both methods gave values agreeing with those of Scheele and Heuse ${ }^{10}$ within the limits of experimental error.

The solids used were prepared by crystallizing commercial C. P. chemicals repeatedly from water. In all cases duplicate determinations were made upon separate samples, and in several cases other duplicate measurements were made upon samples still further purified by crystallization.

\section{Experimental Data}

In presenting the experimental data the following principles have been adopted. All data for a given solid, usually representing measurements of 3 different samples, and each measurement representing the average of several closely agreeing successive readings, have been plotted upon large scale coördinate paper. A smooth curve has been then drawn from the plotted points. The difference in values read from the curve and that of the individual determinations is in most cases very small (less than 0.05 $\mathrm{mm}$.), although a very few determinations show deviations as great as $0.15 \mathrm{~mm}$. It seems probable that the data read from the curves represent the true values within at least $0.05 \mathrm{~mm}$.

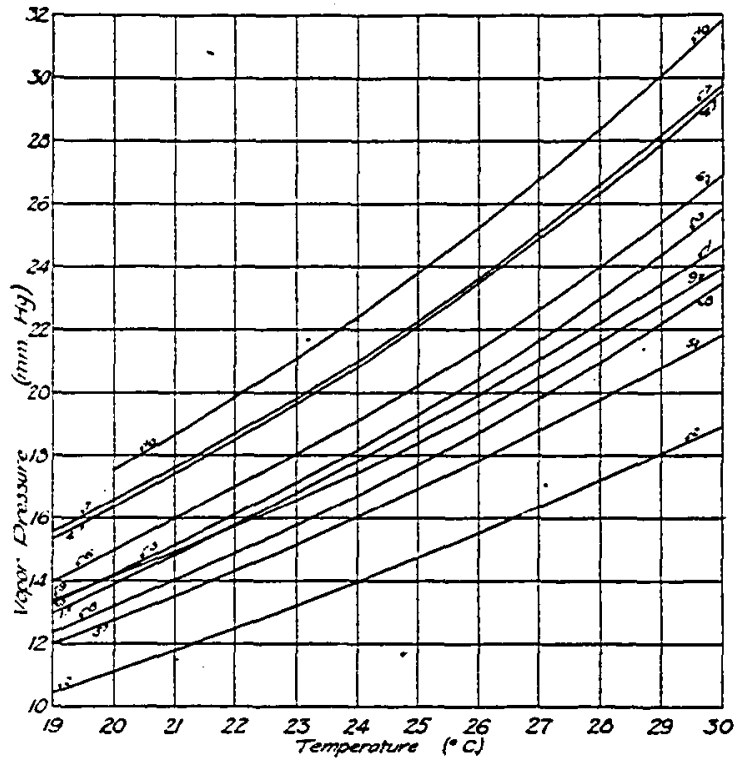

Fig. 1.-Vapor pressures of saturated aqueous solutions.

(1) $\mathrm{NH}_{4} \mathrm{Cl}$; (2) $\mathrm{NH}_{4} \mathrm{NO}_{3}$; (3) $\left(\mathrm{NH}_{4}\right)_{2} \mathrm{SO}_{4}$; (4) $\mathrm{NH}_{4} \mathrm{H}_{2} \mathrm{PO}_{4}$;

(5) $\mathrm{NH}_{4} \mathrm{Cl}+\mathrm{KNO}_{3}$; (6) $\mathrm{KCl}$; (7) $\mathrm{KNO}_{3}$; (8) $\mathrm{NaNO}_{3}$;

(9) Urea; (10) $\mathrm{H}_{2} \mathrm{O}$ (Scheele and Heuse).

ro Scheele and Heuse, Ann. Physik, [1] 31, 731 (1910). 
In Table I are presented for illustration the actual data for sodium nitrate. In Table II are presented the data for all solids studied, read to even degrees from the large-scale curves. The data in Table II are expressed graphically in Fig. 1

\section{TABLE I}

Vapor Pressures of Saturated AqUeods Solutions of Sodtum Nitrate. ExPERTMEANTAL DATa

$\begin{array}{cccc}\begin{array}{c}\text { Temp. } \\ { }^{\circ} \mathrm{C} .\end{array} & \begin{array}{c}\text { Vapor pressure } \\ \text { Mm. } \mathrm{HF}_{5}\end{array} & \begin{array}{c}\text { Temp. } \\ { }^{\circ} \mathrm{C} .\end{array} & \begin{array}{c}\text { Vapor pressure } \\ \mathbf{M m} \mathrm{H} \text {. }\end{array} \\ 20.09 & 13.30 & 26.56 & 19.31 \\ 20.96 & 13.92 & 27.65 & 20.58 \\ 23.03 & 15.84 & 28.99 & 22.08 \\ 23.35 & 16.04 & 29.81 & 23.26 \\ 25.32 & 18.09 & 29.84 & 23.20 \\ 25.39 & 18.01 & & \end{array}$

TABLE II

VAPOR PREssureas of Saturated Aqueous Solutions

Interpolated graphically to even degrees (mm. of $\mathrm{Hg}$ )

\begin{tabular}{|c|c|c|c|c|c|c|c|c|c|}
\hline Temp. & $\mathrm{KCl}$ & $\mathrm{KNO}_{2}$ & $\mathrm{NaN}$ & & $\underset{\mathrm{PO}_{4}}{\mathrm{NH}_{4} \mathrm{H}_{2}}$ & $\begin{array}{l}\left(\mathrm{NH}_{4}\right)_{2-} \\
\mathrm{SO}_{4}\end{array}$ & $\mathrm{NH}_{4} \mathrm{Cl}$ & Urea & $\begin{array}{l}\mathrm{H}_{4} \mathrm{Cl} \text { and } \\
\mathrm{NNO}_{3}\end{array}$ \\
\hline 19.0 & 13.97 & 15.54 & 12.34 & 10.46 & 15.31 & 13.30 & 12.95 & 13.37 & 11.99 \\
\hline 20.0 & 14.97 & 16.58 & 13.06 & 11.10 & 16.33 & 14.20 & 13.90 & 14.15 & 12.73 \\
\hline 21.0 & 15.98 & 17.61 & 14.02 & 11.79 & 17.41 & 15.12 & 14.83 & 14.93 & 13.51 \\
\hline 22.0 & 17.01 & 18.69 & 14.87 & 12.48 & 18.51 & 16.09 & 15.78 & 73 & 14.31 \\
\hline 23.0 & 18.05 & 19.79 & 15.76 & 13.21 & 19.66 & 17.11 & 16.79 & 16.56 & 15.15 \\
\hline 24.0 & 19.10 & 20.96 & 16.70 & 13.96 & 20.82 & 18.06 & 17.80 & 17.44 & 16.03 \\
\hline 25.0 & 20.20 & 22.22 & 17.68 & 14.73 & 22.09 & 19.26 & 18.84 & 18.39 & 16.92 \\
\hline 26.0 & 21.37 & 23.61 & 18.72 & 15.51 & 23.47 & 20.42 & 19.91 & 19.39 & 17.82 \\
\hline 7.0 & 22.64 & 25.08 & 19.81 & 16.35 & 24.88 & 21.67 & 21.03 & 20.46 & 18.80 \\
\hline 28.0 & 23.99 & 26.57 & 20.96 & 17.19 & 26.31 & 23.01 & 22.20 & 21.61 & 19.77 \\
\hline 29.0 & 25.37 & 28.13 & 22.17 & 18.04 & 27.88 & 24.42 & 23.42 & 22.76 & 20.78 \\
\hline 30.0 & 26.88 & 29.71 & 23.46 & 18.91 & 29.57 & 25.82 & 24.66 & 23.93 & 21.83 \\
\hline
\end{tabular}

\section{Discussion of Results}

No earlier data are available for comparison on the values obtained for ammonium chloride,. sulfate, or dihydrogen orthophosphate, urea, or the mixture of potassium nitrate and ammonium chloride. In Table III are listed comparisons of the results with the available data for the other solids studied. Col. 3 gives the earlier data, and Col. 4 the results of the present investigation, read from the curves of Fig. I to correspond to the conditions of Col. 2 .

It will be noted that the value obtained for ammonium nitrate at $20^{\circ}$ is much higher than that of Lescoeur, whose measurements, as noted above, are apparently greatly in error.

The data for sodium nitrate are in very good agreement with the data of Speranski, as well as with the extrapolated value from the measurements of Lincoln and Klein. 
TABLE III

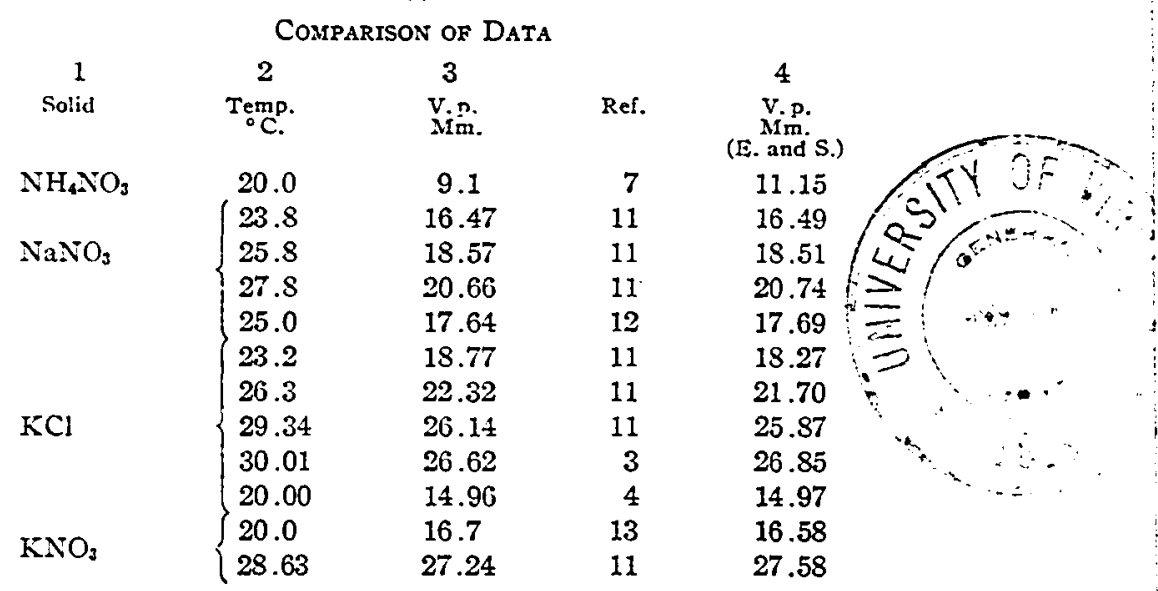

The data for potassium chloride are uniformly lower than those of Speranski; the value at $30^{\circ}$ is somewhat higher than that of Hartung, while the value at $20^{\circ}$ is in complete agreement with the extrapolated value from the careful measurements of Lovelace, Frazer, and Sease.

The value for potassium nitrate at $28.63^{\circ}$ is higher than Speranski's single measurement, but that at $20^{\circ}$ is in fair agreement with the extrapolated data from Landolt-Börnstein "Tabellen."

Altogether there seems no reason to doubt that the data are very close to the correct values.

It should be noted that, as is to be expected, the vapor pressures of the solutions saturated with both ammonium chloride and potassium nitrate are considerably lower than those of solutions saturated with either constituent alone. The bearing of this fact upon the hygroscopic properties of mixtures will be pointed out in a later communication.

\section{Theoretical Considerations}

For solutions as concentrated as those involved in the present investigation it is not to be expected that any simple law will express accurately a relation between the vapor pressure and the temperature and solubility of the solid.

Various empirical interpolation formulas, to express the variation of the vapor pressure of saturated solutions with the temperature, have been proposed by Speranski ${ }^{2}$ but it seems hardly worth while to consider their application to a temperature range as limited as that of the present investigation.

II Speranski, Ref. 2, corrected by the use of the data of Scheele and Heuse, Ref.

10, for pure water.

12 Lincoln and Klein, Ref. 5, extrapolated.

${ }^{13}$ Landolt-Börnstein "Tabellen," 4th Ed. 
From the standpoint of general theory the following may be of interest. If we neglect the volume of the solution in comparison with that of the solvent vapor, and assume that the vapor obeys the gas laws, the ClausiusClapeyron equation becomes

$$
\frac{\mathrm{d}(\ln P)}{\mathrm{d} T}=\frac{Q}{R T^{2}}
$$

where $Q$ is equai to the net heat effect accompanying the evaporation of $1 \mathrm{~mol}$ of solvent vapor and the precipitation of that quantity of solute dissolved in $1 \mathrm{~mol}$ of solvent. $Q$ is evidently equivalent to the heat of combination of one mol of solvent vapor with that quantity of solid sufficient to form a saturated solution, and may thus be regarded as equal to $Q_{1}-S Q_{2}$, where $Q_{1}$ is the heat of evaporation of $1 \mathrm{~mol}$ of pure solvent, $S$ the number of formula weights of solute dissolving in one mol of solvent, and $Q_{2}$ the "integral" heat of solution of one formula weight of solute in the pure solvent.

Since we also have, from Van't Hoff ${ }^{14}$

$$
Q_{2}=R T^{2} i \frac{(\mathrm{d} \ln i S)}{(\mathrm{d} T)}
$$

where $i$ is a factor expressing the deviation of the solution from the laws of ideal solutions, if we place $Q=Q_{1}-S Q_{2}$, and combine Equations 1 and 2 , we obtain

$$
\frac{\mathrm{d}(\ln P)}{\mathrm{d} T}=\frac{Q_{1}}{R T^{2}}-\frac{i S \mathrm{~d}(\ln i S)}{\mathrm{d} T}
$$

whence

$$
\frac{\mathrm{d}(\ln P)}{\mathrm{d} T}=\frac{Q_{1}}{R T^{2}}-\frac{\mathrm{d}(i S)}{\mathrm{d} T}
$$

or

$$
\frac{\mathrm{d}(i \bar{i} S+\ln P)}{\mathrm{d} T}=\frac{Q_{1}}{R T^{2}}
$$

As an approximation we may assume both $Q_{1}$ and $i$ to be constant for a limited temperature range, and on integration we obtain

$$
\ln P_{1}-\ln P_{2}=i\left(S_{2}-S_{1}\right)-\frac{Q_{1}}{R}\left(\frac{1}{T_{3}}-\frac{1}{T_{2}}\right)
$$

For concentrated solutions of the type presented in this paper the values of $i$ may perhaps best be obtained by substituting two experimental values for $P_{1}$ and $P_{2}$. If this is done, the vapor pressures calculated from equation (6) for intermediate temperatures are in good agreement with our experimental results.

14 See Noyes and Sammet, Z. physik. Chem., 43, 513 (1903). 


\section{Summary}

1. The vapor pressures of saturated aqueous solutions of potassium chloride, potassium nitrate, ammonium chloride, ammonium sulfate, ammonium nitrate, ammonium dihydrogen orthophosphate, sodium nitrate, urea, and a mixture of ammonium chloride and potassium nitrate have been measured at temperatures between $20^{\circ}$ and $30^{\circ}$.

2. The relation of the vapor pressures of saturated aqueous solutions to the hygroscopic properties of soluble substances has been briefly discussed.

3. The theory relating the vapor pressure of a saturated solution to the temperature and solubility of the solid has been indicated.

LiNIVERSITY, VIRGINIA 